\title{
Management of Extramedullary Hematopoiesis: Why is a Hematologist's Opinion Important
}

\author{
Ankita Sen*
}

Department of Hematology, NRS Medical College, India

ISSN: 2578-0379

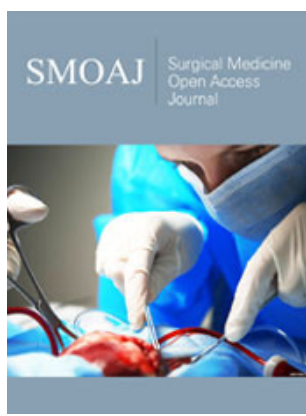

*Corresponding author: Ankita Sen, Consultant hematologist and hematooncologist, India

Submission: 畊 November 2, 2020

Published: 刞January 12, 2021

Volume 4 - Issue 2

How to cite this article: Ankita Sen. Management of Extramedullary Hematopoiesis: Why is a Hematologist's Opinion Important. Surg Med Open Acc J. 4(2). SMOAJ.000582. 2020 DOI: 10.31031/SMOAJ.2021.04.000582

Copyright@ Ankita Sen, This article is distributed under the terms of the Creative Commons Attribution 4.0 International License, which permits unrestricted use and redistribution provided that the original author and source are credited.

\begin{abstract}
Extramedullary Hematopoiesis (EMH) is a compensatory mechanism in response to ineffective hematopoiesis or stress erythropoiesis, in sites other than the bone marrow. The EMH often presents as pseudotumors and may be confused with other benign or malignant tumors. The cause of EMH often is an underlying hematopoietic disorder, and it may be adequately treated by treating the underlying cause. This will avoid unnecessary surgical interventions. Hence, knowledge of this entity is of utmost importance, and careful history, clinical examination and necessary investigations must be carried out before deciding the course of therapy.
\end{abstract}

Keywords: Extramedullary hematopoiesis;Hematopoietic disorders

Abbreviations: EMH: Extramedullary Hematopoiesis; HD: Hematopoietic Disorder

\section{Introduction}

Hematopoietic tissue is normally present in the bone marrow and is responsible for hematopoiesis or production of different lineages of blood cells. Extramedullary hematopoiesis (EMH) is a compensatory mechanism in response to ineffective hematopoiesis or stress erythropoeisis, that leads to production of hematopoietic cells outside the marrow in patients with Thalassemia intermedia or Non-transfusion dependent Thalassemia (NTDT) [1]. The EMH pseudotumors are more prevalent in NTDT (20\%) than in Transfusion dependent thalassemias, like $\beta$ Thalassemia major $(<1 \%)[2,3]$. EMH is commonly seen in $\mathrm{HbE} \beta$-thalassemia, a disease very common in the eastern part of India and many South East Asian countries, and $\beta$ Thalassemia Intermedia [2,4]. It may also occur in Myeloproliferative neoplasms (MPN), commonly Myelofibrosis [5]. Rarer causes include lymphomas and leukemias [6]. In patients with lymphomas or leukemias, EMH may occur due to infiltration of the bone marrow by malignant cells [6]. EMH is caused by the expansion of the hematopoietic tissue in the extramedullary tissues, such as liver, spleen and paravertebral tissue [2]. This manifests as hepatosplenomegaly or extramedullary pseudotumors [2,3]. Many other sites may be involved, including lymph nodes, thymus, heart, breasts, prostate, broad ligaments, kidneys, adrenal glands, pleura, retroperitoneal tissue, skin, peripheral and cranial nerves, or the spinal canal. The lymph nodes are the commonest sites of involvement for EMH [7]. Of all the extramedullary sites, the paraspinal involvement (11-15\%) is an emergency situation because of intense pain or paresthesias arising out of compression of the spine [8,9]. However, more than $80 \%$ cases may only be detected asymptomatically [2]. The thoracic region followed by the lumbar vertebral region are the most commonly involved paraspinal sites [10].

Skiagrams may reveal paraspinal masses or hemolytic anemia related widening of the ribs or calvaria [2]. Radiological diagnosis, by Magnetic Resonance Imaging or Computed Tomography, is an essential tool for the diagnosis of EMH [11,12]. Currently, MRI is the preferred choice of diagnosis and follow-up, as it can help in assessing the anatomy and soft tissue structure of the EMH pseudotumor [2]. EMH tissue comprises of immature and mature precursors of the erythroid, myeloid lineages, and megakaryocytes [7].

Presentation of the problem: It is not very uncommon to find patients being referred from the Surgery, Neurology or Neurosurgery departments. The patient may present to the Neurology/Neurosurgery departments with complaints of back pain, paresthesias, paraparesis or paraplegia of the lower limbs [9]. The patient may also present with abdominal 
pain or a swelling in different parts of the body to the Surgery department. Zhang et al. [1] have described two case reports, one where multiple paraspinal masses were detected in a patient of $\alpha$ Thalassemia, and the second, where multiple masses were detected in the thorax in a patient of $\beta$ Thalassemia [1]. In both instances, the diagnosis was made by a surgical biopsy and no further surgical therapy was performed. Macki et al. [13] have described the rare idiopathic presacral EMH tumor, without an underlying past or current hematological disorder [13].

Sometimes, the spleen may also have a EMH as a pseudotumor instead of a splenic diffuse hyperplasia [14]. This spleen was excised and was later found to be a splenic hemangioma with EMH. In this case report, no underlying hematopoietic disorder were diagnosed [14]. Another case report described how a 45-year-old lady with an anterior neck swelling was found to have EMH in the thyroid gland by Fine Needle Aspiration (FNA) technique. This patient was later diagnosed with an underlying Chronic Myeloid Leukemia (by clinical examination and blood tests) [15]. She was treated with Imatinib and surgery was not required. Surgery may be required if there are compressive symptoms [15]. In a 14-yearold boy diagnosed with Acute leukemia (clinically and from blood and bone marrow investigations), an FNA cytology was conducted from a large lymph node, and leukemic cells and EMH were detected [16]. This patient will require therapy of acute leukemia, rather than surgery. Another case report described a 12-yearold boy with hemolytic anemia, who was diagnosed with a well circumscribed mass in the right kidney [17]. EMH was diagnosed by FNA cytology and nephrectomy was avoided. FNA is a cost effective and quick procedure for diagnosing $\mathrm{EMH}$, however, biopsy from the extramedullary pseudotumor is the diagnostic test for EMH $[7,18]$. In most of the published literature, the hematological disorder was either pre-diagnosed or newly diagnosed in the patient from blood/ bone marrow examination or by FNA/biopsy from the site of EMH.

\section{Management}

The management of EMH depends on the underlying cause. In any situation where EMH is detected in an extramedullary organ, the underlying cause should be evaluated thoroughly, as often a hematopoietic disorder may be missed $[17,19]$. A thorough history taking, which must include a history of transfusion requirement or family history, and a clinical examination, including liver, spleen examination, evaluation of pallor, icterus or hemolytic facies, are a must. A complete hemogram and peripheral smear examination must be sent for, and based on the findings, further blood or bone marrow investigations are to be undertaken. Radiological investigations are to be undertaken to assess the extent and site of the EMH. Often, an FNA or biopsy examination may be carried out when the tumor arises in a rarer site, usually before the patient is referred to a hematologist. The commonest cause of EMH, i.e., Thalassemia will need to be managed by regular and adequate transfusions, with or without Foetal haemoglobin inducing agents [2]. In cases which lead to compressive symptoms or signs requiring immediate attention, specially EMH in the paravertebral regions, radiotherapy or surgical interventions may be considered [13]. The causes of EMH, like MPN, Lymphomas or Leukemias have to be treated in order to treat the EMH. In case of idiopathic causes of $\mathrm{EMH}$, the treatment is according to the symptomatology [13].

\section{Conclusion}

Thus, EMH must be kept in mind as a differential diagnosis in patients with a hemoglobinopathy or other hematological disorders, who present with a mass in any part of the body, including the paravertebral region. Any symptomatic tumor in the paravertebral region or elsewhere, must be treated as an emergency, and treated accordingly. History, clinical findings, a complete hemogram, radiological findings and sometimes an FNA or biopsy, will help to clinch the diagnosis, and avoid unnecessary surgical interventions.

\section{References}

1. Zhang HZ, Li Y, Liu X, Chen BR, Yao GH, et al. (2016) Extramedullary hematopoiesis: A report of two cases. Exp Ther Med 12(6): 3859-3862.

2. Taher A, Musallam K, Cappellini MD (2017) Guidelines for the management of non-transfusion dependent thalassaemia (NTDT) Extramedullary haematopoiesis. $\left(2^{\text {nd }}\right.$ edn), Thalassemia International Federation, Cyprus, pp. 90-99.

3. Taher AT, Musallam KM, Karimi M, El Beshlawy A, Belhoul K, et al. (2009) Overview on practices in thalassemia intermedia management aiming for lowering complication rates across a region of endemicity: The optimal care study. Blood 115(10): 1886-1892.

4. Mondal SK, Mandal S (2016) Prevalence of thalassemia and hemoglobinopathy in eastern India: A 10-year high-performance liquid chromatography study of 119,336 cases. Asian Journal of Transfusion Science 10(1): 105-110.

5. Kim $\mathrm{CH}$ (2010) Homeostatic and pathogenic extramedullary hematopoiesis. J Blood Med 1: 13-19.

6. Bothale A, Bothale K, Mahore S, Dongre (2018) Cytodiagnosis of coexistence of leukemic infiltration and extramedullary hematopoiesis in a cervical lymph node, in t cell leukemia patient. J Cytol 35(3): 189192.

7. Kapatia G, Kaur A, Rastogi P, Sreedharanunni S, Gupta P, et al. (2020) Extramedullary hematopoiesis: Clinical and cytological features. Diagn Cytopathol 48(3): 191-196.

8. Musallam MK, Rivella S, Vichinsky E, Rachmilewitz EA (2013) Nontransfusion dependent thalassemias. Haematologica 98(6): 833-844.

9. Haidar R, Mhaidli H, Tacher AT (2010) Paraspinal extramedullary hematopoiesis in patients with thalassemia intermedia. Eur Spine J 19(6): 871-878.

10. Tsitouridis J, Stamos S, Hassapopoulou E, Tsitouridis K (1999) Extramedullary paraspinal hematopoiesis in thalassemia: CT and MRI evaluation. Eur J Radiol 30(1): 33-38.

11. Haidar S, Neira CO, Shroff M, Gilday D (2005) Intracranial involvement in extramedullary hematopoiesis: Case report and review of the literature. Pediatr Radiol 35(6): 630-634.

12. Debard A, Demasles S, Camdessanché JP, Duband S, Mohammedi R, et al. (2009) Dural localization of extramedullary hematopoiesis. Report of a case. J Neurol 256(5): 837-838.

13. Macki M, Bydon M, Papademetriou K, Gokaslan Z, Bydon A, et al. (2013) Presacral extramedullary hematopoiesis: An alternative hypothesis. J Clin Neurosci 20(12):1664-1668. 
14. Hudson JB, Murad FM, Kunkel JE, Collins BT (2013) Endoscopic ultrasound guided fine-needle aspiration of a splenic hemangioma with extramedullary hematopoiesis. Diagn Cytopathol 41(12):1086-1090.

15. Kishore M, Kaushal M, Marwah S, Sharma M, Sharma N, et al. (2019) Cytodiagnosis of extramedullary hematopoiesis in thyroid gland unravelling an asymptomatic hematological malignancy. Diagn Cytopathol 47(4): 320-324.

16. Bothale A, Bothale K, Mahore S, Dongre T (2018) Cytodiagnosis of coexistence of leukemic infiltration and extramedullary hematopoiesis in a cervical lymph node, in T cell leukemia patient. J Cytol 35(3): 189192.
17. Ahuja S, Grover G, Jha AK, Sodhi K, Bansal D, et al. (2011) Extramedullary hematopoiesis presented as solitary renal mass: A case report with review of literature. Diagn Cytopathol 39(6): 435-437.

18. Tan TC, Tsao J, Cheung FC (2002) Extramedullary haemopoiesis in thalassemia intermedia presenting as paraplegia. J Clin Neurosci 9: 721725.

19. Akbulut S, Yavuz R, Akansu B, Sogutcu N, Arikanoglu Z, et al. (2011) Ectopic bone formation and extramedullary hematopoiesis in the thyroid gland: Report of a case and literature review. Int Surg 96(3): 260-265. 